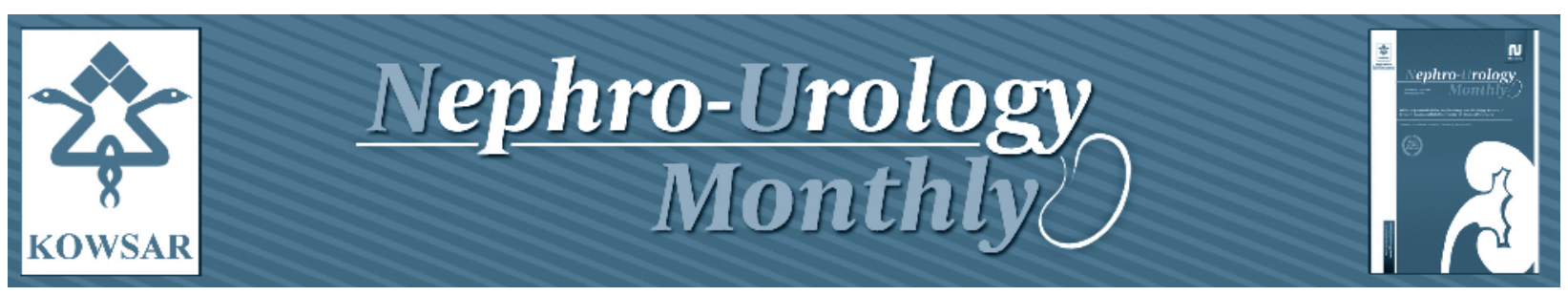

\title{
The Relationship Between Erythropoietin Resistance and Antibody Response to Hepatitis B Vaccine in Hemodialysis Patients
}

\author{
Baris Afsar ${ }^{1, *}$ \\ ${ }^{1}$ Department of Medicine, Division of Nephrology, Konya Numune State Hospital, Konya, Turkey \\ ${ }^{*}$ Corresponding author: Baris Afsar, Department of Nephrology, Konya Numune State Hospital, 42060, Konya, Turkey. Tel: +90-3322354500, Fax: +90- \\ 33223567, E-mail: afsarbrs@yahoo.com.
}

\section{A B S T R A C T}

Background: Seroconversion following Hepatitis B virus (HBV) vaccine in hemodialysis (HD) patients has been shown to be suboptimal. Nutritional and immunological factors were shown to influence the seroconversion related to HBV vaccination in HD patients. Resistance to erythropoiesis stimulating agents (ESA) for correction of anemia has also been shown to be associated with nutrition and inflammation in these patients.

Objectives: The aim of the current study was to analyze the relationship between anti-HBs response and erythropoietin (EPO) resistance in HD patients.

Patients and Methods: Demographics, clinical characteristics, laboratory parameters and the data about vaccination status were obtained from dialysis charts and vaccination registries retrospectively. To calculate the EPO resistance ESA hypo responsiveness index (EHRI) was used. The EHRI was calculated through deviding the weekly dose of EPO by per kilogram of body weight divided by the hemoglobin level. Patients were divided into non-seroconversion (anti-HBs titers were $<10 \mathrm{IU} / \mathrm{L}$ ) and seroconversion groups (anti-HBs titers were $\geq 10 \mathrm{IU} / \mathrm{L}$ ) after completion of the four-dose vaccination schedule.

Results: In total 97 patients were enrolled. For the entire group, stepwise linear regression analysis revealed that square root transformed anti-HBs levels were independently associated with age $(\mathrm{P}=0.016)$, blood urea nitrogen $(\mathrm{P}=0.019)$, high sensitive C-Reactive Protein ( $\mathrm{P}$ $=0.009)$, and square root transformed EHRI $(P=0.019)$. Logistic regression analysis have also demonstrated that blood urea nitrogen $(\mathrm{P}=0.002)$, creatinine $(\mathrm{P}=0.046)$, albumin $(\mathrm{P}=0.01)$ and square root transformed EHRI $(\mathrm{P}=0.011)$ were independently related to seroconversion.

Conclusions: EPO resistance was negatively associated with anti-HBs levels and seroconversion. More studies are needed to highlight the underlying mechanisms regarding EPO resistance and response to HBV vaccination in HD patients.

Keywords: Erythropoietin; Hepatitis B; Renal Dialysis; Vaccines

Copyright @ ( 2013, Nephrology and Urology Research Center; Published by Kowsar Corp.

Article type: Research Article; Received: 01 Nov 2012; Revised: 04 Dec 2012; Accepted: 22 Dec 2012; Epub: 28 May 2013 ; Ppub: 01 Jul 2013

Implication for health policy/practice/research/medical education:

Erythropoietin response and hepatitis B vaccine response may be interrelated. Whether additional doses of hepatitis B vaccine will improve erythropoietin resistance needs to be determined in hemodialysis patients.

Please cite this paper as:

Afsar B. The Relationship Between Erythropoietin Resistance and Antibody Response to Hepatitis B Vaccine in Hemodialysis Patients. Nephro Urol Mon.2013;5(3): 806-12. DOI: 10.5812/numonthly.8919

Copyright ( 2013, Nephrology and Urology Research Center; Published by Kowsar Corp.

This is an Open Access article distributed under the terms of the Creative Commons Attribution License (http://creativecommons.org/licenses/by/3.0), which permits unrestricted use, distribution, and reproduction in any medium, provided the original work is properly cited. 


\section{Background}

Patients on hemodialysis (HD) are at a relatively high risk for exposure to hepatitis B virus (HBV) infection. Therefore, vaccination against HBV has been strongly recommended for the prevention of infection in HD patients. However, despite the availability of vaccination programs, antibody production against HBV surface antigen (anti-HBs) in patients with chronic renal disease is suboptimal. While the percentage of seroconversion following $\mathrm{HBV}$ vaccination is $90 \%$ in healthy individuals, it is only $50-70 \%$ in HD patients (1). Various factors such as genetic predisposition, age, gender, obesity, smoking and concurrent illness has been recognized as possible causes of low responsiveness to HBV vaccine (2-4). Apart from these factors, indices of nutritional status $(1,5)$ and immune status $(6-10)$ have been shown to influence the seroconversion related to $\mathrm{HBV}$ vaccination.

Anemia is a common complication in HD patients and is characterized by a relative deficiency of erythropoietin (EPO) secretion from the diseased kidney relative to the degree of anemia. Therefore, EPO therapy has become the standard treatment in HD patients. Although most HD patients respond adequately to erythropoiesis stimulating agents (ESA), some of them did not respond well to ESA; so-called ESA resistance (11). ESA resistance is defined as a failure to achieve target hemoglobin/ hematocrit levels despite a higher than usual dose of ESA, or a continuous need for this higher dose to maintain target hemoglobin/hematocrit levels (12). In recent studies, the ESA hyporesponsiveness index (EHRI), calculated as the weekly dose of EPO divided by per kilogram of body weight divided by the hemoglobin level (g/dL) has been considered useful to assess the EPO resistance. The EHRI can be easily calculated in the clinic and was directly related to co morbidity and mortality in patients on hemodialysis (HD) $(13,14)$. It has been clearly shown that one of the most important factors for erythropoietin resistance is the presence of malnutrition and inflammation in HD patients $(11,15,16)$.

\section{Objectives}

Since both responses to HBV vaccination and EPO resistance were related with nutritional and inflammatory status in HD patients, it could be possible that these conditions could be interrelated. Thus the current study has been performed to analyze the relationship between anti-HBs response and EPO resistance in HD patients.

\section{Patients and Methods}

This is a retrospective study of in center HD patients who were followed at least for 12 months in the dialysis unit of a state hospital. Baseline demographic data including age, sex, etiologies of kidney disease, type of HD access, presence of diabetes, presence of coronary artery disease were collected. In addition, laboratory results (except from ferritin and parathyroid hormone), kinetic urea modeling for calculation of dialysis dose and total erythropoietin dos- age were also examined over the duration of vaccination administration (at 0,1,2 and 6 months except from ferritin and parathyroid hormone which were analyzed 0,3 and 6 months) and the mean of these parameters were used for the final analysis. Body mass index (BMI) was calculated as the ratio of dry weight in kilograms (end-dialysis weight) to height squared (in square meters). Each session lasted for $4-5 \mathrm{~h}$ for all patients with blood flow rates of $300-400 \mathrm{~mL} /$ min using standard bicarbonate dialysis solution. All patients were virtually anuric and clinically euvolemic. Urea kinetic modeling was performed in order to assess the delivered dose of dialysis using the formula:

\section{spKt/V: $-\operatorname{Ln}(\mathrm{R}-0.008 \times \mathrm{t})+(4-[3.5 \times \mathrm{R}]) \mathrm{XUF} / \mathrm{W}$}

Where spKt/V is a single-pool Kt/V, R is the ratio of postdialysis to pre-dialysis serum urea nitrogen, $t$ is the time on dialysis in hours, UF is the amount of ultrafiltration in liters and $\mathrm{W}$ is the post-dialysis body weight in kilograms.

Total EPO dose was also recorded for the patients. All the patients were using erythropoietin alpha or erythropoietin beta as ESA. None of the patients received darbepoetin during the study period. All of the patients received recombinant hepatitis B vaccine, given intramuscularly in the deltoid muscle with double doses $(40 \mathrm{mcg})$ in a fourth-dose schedule at 0,1,2 and 6 months. The data about vaccination status were obtained from dialysis charts and vaccination registries. Immunogenicity or antibody response was determined by the levels of anti-HBs within 1-3 months after the last dose of vaccine. After the initial check for anti-HBs levels, regular anti-HBs levels were checked every 6 months. Booster doses were applied to patients whose anti-HBs levels were decreased below the protective level. Anti-HBs titers were measured using a commercially available enzyme immunoassay (Bioelisa, AntiHb-sAg, Biokit, Barcelona, Spain). We separated the patients into non-seroconversion and seroconversion groups according to their anti-HBs titers: the non- seroconversion group consists of patients whose antiHBs titers were $<10 \mathrm{IU} / \mathrm{L}$ after completion of the four-dose vaccination schedule (this group also involves patients who were nonresponsive to booster doses) and the seroconversion group consists of patients whose anti-HBs titers were $\geq 10 \mathrm{IU} / \mathrm{L}$ (this group also involves patients whose anti-HBs levels decreased below the protective levels by time, but responded to a booster dose).

\subsection{Statistics}

Statistical analysis was performed with the SPSS software (Statistical Package for the Social Sciences, version 15.0, SSPS Inc.,Chicago, Ill, USA). Data were shown as mean, standard deviation or percentage where appropriate. Results were considered statistically significant if the 2 -tailed P value was $<0.05$. Data was checked for normality. Comparisons of the groups were assessed by means of the Student's T-test for normally distributed variables and by the Mann-Whitney $\mathrm{U}$ test for non-normally distributed variables. For the analysis of EHRI levels between the 3 groups; Kruskal-Wallis test was used. For the post hoc analysis of EHRI between these 
groups; Bonferroni corrected Mann-Whitney U test was used. For the analysis of categorical variables, we used the Chi-Square test and Fisher's exact test as appropriate. Pearson correlation coefficient $r$ and Spearman correlation coefficient rho were used for the correlation of normally and non-normally distributed variables respectively. Stepwise linear regression was used for the analysis of independent factors (age, gender, HD duration, BMI, presence of smoking, presence of diabetes mellitus, spKt/V, blood urea nitrogen, creatinine, albumin, High sensitive $C$ reactive protein (Hs-CRP) and square root transformed EHRI, related with square root transformed anti-HBs levels (as a dependent parameter)). Logistic regression analysis was also used with the same independent parameters to determine anti-HBs response status (seroconversion vs. non-seroconversion groups, as the dependent variable).

\section{Results}

Initially 140 patients were enrolled. The inclusion criterion was stable HD patients who were on HD treatment for at least of 12 months. The exclusion criteria were lack of regular 4 doses of vaccination (15 patients), incomplete laboratory data (14 patients), transfer to other centers ( 5 patients), anti-HCV positivity (4 patients), iron deficiency ( 5 patients) (defined as a serum ferritin level of $<200 \mathrm{ng} / \mathrm{mL}$ or transferring saturation $<20 \%$ ).

Table 1. The Comparative Sociodemographic and Laboratory Characteristics of Patients With and Without Seroconversion

\begin{tabular}{|c|c|c|c|}
\hline Parameters & $\begin{array}{l}\text { Seroconversion } \\
\text { Group }(n=76)\end{array}$ & $\begin{array}{l}\text { Non-seroconversion } \\
\text { Group }(\mathbf{n}=\mathbf{2 1})\end{array}$ & P value \\
\hline Age, $\mathbf{y}^{\mathrm{a}}$ & $46.8 \pm 14.3$ & $52.2 \pm 6.1$ & $0.012^{\mathrm{b}}$ \\
\hline Male/Female, No. ${ }^{c}$ & $48 / 28$ & $11 / 10$ & $0.371^{\mathrm{d}}$ \\
\hline Hemodialysis duration, mo ${ }^{a}$ & $86.9 \pm 53.7$ & $81.9 \pm 52.4$ & $0.706^{\mathrm{e}}$ \\
\hline Body Mass Index, $\mathrm{kg} / \mathrm{m}^{2 a}$ & $23.1 \pm 3.5$ & $24.4 \pm 5.0$ & $0.249^{\mathrm{e}}$ \\
\hline Smoker/non smoker, No. & $27 / 49$ & $8 / 13$ & $0.828^{\mathrm{d}}$ \\
\hline Previous renal transplantation (present/absent), No. & $16 / 60$ & $1 / 20$ & $0.109^{f}$ \\
\hline Diabetes mellitus (present/absent), No. & $13 / 63$ & $5 / 16$ & $0.530^{\mathrm{f}}$ \\
\hline Coronary artery disease (present/absent), No. & $21 / 55$ & $9 / 12$ & $0.181^{d}$ \\
\hline Hemoglobin, $g / \mathbf{L}^{\mathrm{a}}$ & $104.1 \pm 9.7$ & $103.6 \pm 7.9$ & $0.797^{\mathrm{C}}$ \\
\hline Blood urea nitrogen, $\mathrm{mmol} / \mathrm{L}^{\mathrm{a}}$ & $25.8 \pm 5.1$ & $21.5 \pm 5.9$ & $0.009^{\mathrm{e}}$ \\
\hline Creatinine, $\mu \mathrm{mol} / \mathrm{L}^{\mathrm{a}}$ & $804.4 \pm 212.2$ & $760.2 \pm 150.3$ & $0.360^{\mathrm{e}}$ \\
\hline Albumin, $g / \mathbf{L}^{\mathrm{a}}$ & $38.7 \pm 5.7$ & $34.3 \pm 6.8$ & $0.004^{\mathrm{C}}$ \\
\hline Calcium, mmol/ $\mathbf{L}^{\mathrm{a}}$ & $2.21 \pm 0.16$ & $2.15 \pm 0.22$ & $0.219^{\mathrm{b}}$ \\
\hline Phosphorus, mmol// $\mathbf{L}^{\mathrm{a}}$ & $1.67 \pm 0.41$ & $1.52 \pm 0.23$ & $0.213^{\mathrm{e}}$ \\
\hline Alanine aminotransferase, $\mu$ kat $/ L^{a}$ & $0.27 \pm 0.08$ & $0.26 \pm 0.13$ & $0.478^{\mathrm{e}}$ \\
\hline Aspartate aminotransferase, $\mu \mathrm{kat} / \mathrm{L}^{\mathrm{a}}$ & $0.27 \pm 0.18$ & $0.27 \pm 0.09$ & $0.316^{\mathrm{e}}$ \\
\hline Total Cholesterol, mmol// $\mathrm{L}^{\mathrm{a}}$ & $4.48 \pm 1.03$ & $4.42 \pm 0.88$ & $0.979^{\mathrm{e}}$ \\
\hline $\mathrm{HDL}^{\mathrm{c}}$-Cholesterol, $\mathrm{mmol} / \mathrm{L}^{\mathrm{a}}$ & $1.08 \pm 0.33$ & $1.17 \pm 0.27$ & $0.265^{\mathrm{e}}$ \\
\hline LDL $^{\mathrm{C}}$-Cholesterol, $\mathbf{m m o l} / \mathrm{L}^{\mathrm{a}}$ & $2.58 \pm 1.05$ & $2.40 \pm 0.71$ & $0.568^{\mathrm{e}}$ \\
\hline Triglyceride, $\mathrm{mmol} / \mathrm{L}^{\mathrm{a}}$ & $1.88 \pm 0.92$ & $2.10 \pm 0.91$ & $0.457^{\mathrm{e}}$ \\
\hline Intact Parathyroid Hormone, pg/mL ${ }^{\mathrm{a}}$ & $200.5 \pm 179.4$ & $201.9 \pm 160.4$ & $0.716^{\mathrm{e}}$ \\
\hline Serum Iron, $\mu \mathrm{mol} / \mathrm{L}^{\mathrm{a}}$ & $10.76 \pm 5.34$ & $11.35 \pm 5.69$ & $0.668^{\mathrm{e}}$ \\
\hline Ferritin, $\mathbf{n g} / \mathbf{m L}^{\mathrm{a}}$ & $336.8 \pm 168.8$ & $307.2 \pm 197.0$ & $0.220^{\mathrm{e}}$ \\
\hline Hs-CRP ${ }^{\mathrm{b}}, \mathbf{m g} / \mathbf{d L}^{\mathrm{a}}$ & $6.62 \pm 8.30$ & $3.73 \pm 4.84$ & $0.262^{\mathrm{e}}$ \\
\hline $\operatorname{spKt} / V^{\mathrm{a}}$ & $1.37 \pm 0.19$ & $1.32 \pm 0.19$ & $0.272^{b}$ \\
\hline EHRI $^{\mathrm{C}}$ & $6.91 \pm 3.44$ & $9.19 \pm 2.85$ & $0.003^{\mathrm{e}}$ \\
\hline \multicolumn{4}{|c|}{$\begin{array}{l}\text { a mean } \pm \text { Standart Deviation } \\
\text { b P value is based on Student t test } \\
{ }_{\text {Abbreviations: EHRI, Erythropoiesis stimulating agent hyporesponsiveness index; HDL, High density lipoprotein; Hs-CRP, High Sensitive C-reactive }} \\
\text { protein } \\
\mathrm{d}_{\text {P value is based on chi square test }} \\
\text { e P value is based on Mann whitney test } \\
\mathrm{f}_{\text {P value is based on Fishers exact test }}\end{array}$} \\
\hline
\end{tabular}


There were no patients in our study with a malignancy, showing antibodies against human immunodeficiency virus or taking intradialytic nutritional support during the study period. The final patient population composed of 97 patients. Etiologies for ESRD were as follows; diabetes mellitus in 18, hypertension in 21, glomerulonephritis in 14, vesicourethral reflux and pyelonephritis in 12, nephrolithiasis in 7 , polycystic kidney disease in 4 , amyloidosis in 4 , systemic lupus erythematosus in 1 and unknown in 16 patients. The HD access was the arterio-venous fistula for 79 patients, arterio-venous graft for 11 patients and central venous catheters for 7 patients. Among the 97 patients, 21 (21.6\%) comprised the non-seroconversion group, whereas 76 patients (78.4\%) comprised the seroconversion group. The comparative sociodemographic and laboratory characteristics of patients with seroconversion and non- seroconversion are given in Table 1. The patients were further divided into 3 groups according anti-HBs levels: Group 1 $(\mathrm{n}=21)$ : anti-HBs titer $\leq 10 \mathrm{mIU} / \mathrm{mL}$ (non-seroconversion group). Group $2(\mathrm{n}=29)$ : anti-HBs titer between 10-99
$\mathrm{mIU} / \mathrm{mL}$ (weak seroconversion). Group 3 ( $\mathrm{n}=47$ ): anti-HBs titer $>100 \mathrm{mIU} / \mathrm{mL}$ (strong seroconversion). The mean of EHRI were $9.19 \pm 2.85,7.30 \pm 3.22$ and $6.68 \pm 3.59$ in the 3 groups respectively $(\mathrm{P}=0.008)$. Post hoc analysis of the three groups revealed that Groups 1 and 2 were different with respect to EHRI $(\mathrm{P}=0.031)$ as with group 1 and $3(\mathrm{P}$ $=0.003)$. However the EHRI were not different between group 2 and $3(\mathrm{P}=0.297)$ (Figure 1$)$.

For the entire group, spearman correlation analysis revealed that anti-HBs titers were correlated with age: (rho: -0.265, $\mathrm{P}=0.009$ ), blood urea nitrogen (rho: $0.290, \mathrm{P}=$ 0.004) albumin, (rho: $0.206, \mathrm{P}=0.043$ ), EHRI (rho: $-0.249, \mathrm{P}$ $=0.014$ ) and total EPO dose (rho: $-0.206, \mathrm{P}=0.043)$. The correlation of square root transformed anti-HBs and square root transformed EHRI are shown in Figure 2 (r: -0.210, P = 0.039). Stepwise linear regression of independent factors (as mentioned above) related with square root transformed anti-HBs levels are shown in Table 2. The logistic regression analysis of independet factors related with seroconversion vs. non-seroconversion was given in Table 3.

Table 2. Stepwise Linear Regression of Independent Factors Related With Squarerroot Transformed Anti-Hbs Levels

\begin{tabular}{|c|c|c|c|c|}
\hline & $\mathbf{B}^{\mathrm{a}}$ & Beta $^{b}$ & Confidence Interval & Pvalue \\
\hline Constant & 13.337 & - & $3.567-23.106$ & 0.008 \\
\hline Age & -0.119 & -0.233 & $-0.216-(-0.023)$ & 0.016 \\
\hline Blood Urea Nitrogen & 0.099 & 0.227 & $0.017-0.181$ & 0.019 \\
\hline High Sensitive C-Reactive Protein & 0.214 & 0.246 & $0.055-0.373$ & 0.009 \\
\hline Square root TransformedEHRI ${ }^{\mathrm{C}}$ & -2.318 & -0.219 & $-4.250-(-0.386)$ & 0.019 \\
\hline
\end{tabular}

${ }_{\mathrm{B}}$, regression coefficient

$\mathrm{b}$ Beta, Partial correlation coefficient

${ }^{\mathrm{c}}$ EHRI, erythropoiesis stimulating agents hyporesponsiveness index

Table 3. Logistic Regression Analysis of Independent Factors Related With Seroconversion

\begin{tabular}{|c|c|c|c|}
\hline & $\operatorname{Exp}(B)^{a}$ & $\begin{array}{l}95.0 \% \text { Confidence Interval for } \\
\operatorname{EXP}(B)\end{array}$ & P value \\
\hline Age & 0.955 & $0.898-1.016$ & 0.143 \\
\hline Gender (being female) & 0.178 & $0.029-1.116$ & 0.065 \\
\hline HD duration & 1.004 & $0.990-1.019$ & 0.561 \\
\hline Body Mass Index & 0.848 & $0.686-1.050$ & 0.130 \\
\hline Presence of Diabetes & 0.490 & $0.090-2.673$ & 0.411 \\
\hline Smoking & 0.191 & $0.036-1.017$ & 0.052 \\
\hline Blood Urea Nitrogen & 1.133 & $1.047-1.226$ & 0.002 \\
\hline Creatinine & 1.811 & 1.0113 .246 & 0.046 \\
\hline Albumin & 7.002 & $1.580-31.025$ & 0.01 \\
\hline High Sensitive C-Reactive Protein & 1.051 & $0.948-1.164$ & 0.346 \\
\hline Square root TransformedEHRI ${ }^{\mathrm{b}}$ & 0.184 & $0.050-0.684$ & 0.011 \\
\hline spKt/V & 5.237 & $0.090-9.987$ & 0.425 \\
\hline
\end{tabular}

${ }^{a} \operatorname{Exp}(\mathrm{B})$, Odds ratio

b Abbreviation: EHRI, erythropoiesis stimulating agents hyporesponsiveness index 


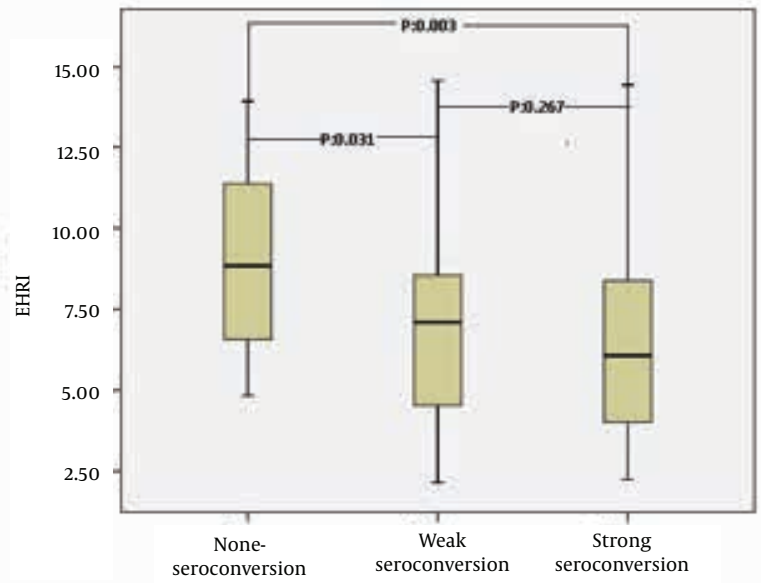

Figure 1. The Comparision of Erythropoiesis Stimulating Agents Hyporesponsiveness Index Among Hemodialysis Patients With Non-Seroconversion, Weak Seroconversion and Strong Seroconversion

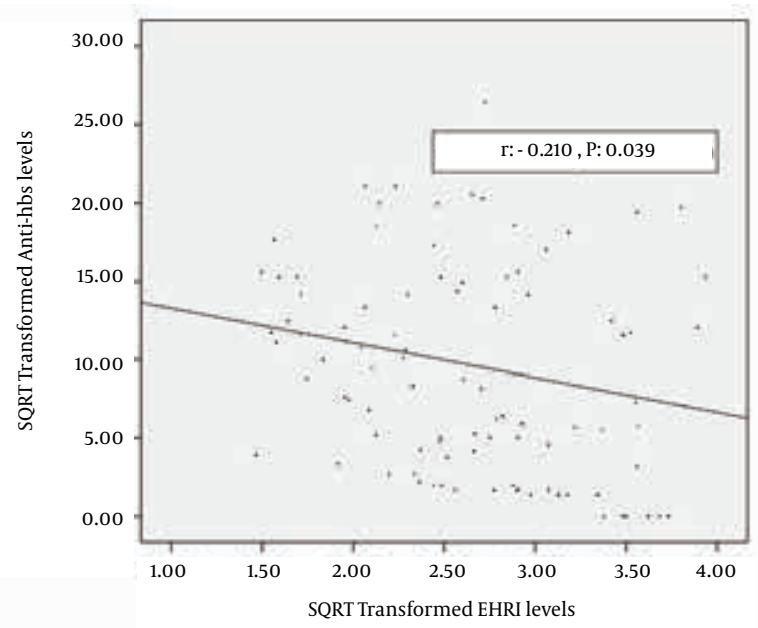

Figure 2. The Scatter Plot Graphic Between Square Root Transformed Erythropoiesis Stimulating Agents Hyporesponsiveness Index and Square Root Transformed Anti-Hbs Levels

\section{Discussion}

In the current study, it was firstly demonstrated that EPO resistance, as evaluated by EHRI, was negatively associated with both anti-Hbs levels (taking as a continuous variable) and seroconversion status (taking as a categorical variable) in stable HD patients.

It is well known that in HD patients anti-HBs levels achieved after HBV vaccination is suboptimal (1). Various factors such as genetic predisposition, age, gender, obesity, smoking and concurrent illness have been recognized as possible causes for none or low responsiveness to HBV vaccine (2-4). Apart from these factors, nutritional status $(1,5)$ and immune status $(6-10)$ have also influenced response rates. Anemia which is a common condition in HD patients is mostly due to relative deficiency of EPO secretion from the diseased kidney relative to the degree of anemia. Therefore, EPO therapy has become the standard treatment for the anemia of CKD (chronic kidney disease). Although most HD patients respond adequately to ESA, some of them did not respond well to ESA; so-called ESA resistance (11). It was clearly shown that one of the most important factors for erythropoietin resistance is the presence of malnutrition and inflammation in HD patients $(11,15,16)$. Since response to $\mathrm{HBV}$ vaccination and EPO resistance were related with nutritional and inflammatory status in HD patients, it could be possible that these conditions (vaccination response to HBV and EPO resistance) could be interrelated. Indeed the current study has shown that as EPO resistance (evaluated by EHRI) increased; response to HBV vaccination decreased. Previously, only one study has shown that EPO therapy did not significantly influence antibody responses to immunization with HBV vaccine. However, the authors took EPO therapy as a categorical variable and did not calculate EPO resistance. Additionally, they did not specifically address the anti-Hbs levels (10).

Why EPO resistance and response to HBV vaccine is inversely associated? Currently the answer is not known but speculations can be made. One of the possible mechanisms may be the immune suppression that was experienced by most HD patients $(10,17)$. Specific antibody production after HBV vaccination is generated via B-cell activation by CD4+ Th1-helper (class II) and CD8+ CTL-cytotoxic T-cell (class I restricted T-cell) responses $(18,19)$. In this regard, it has been shown that monocyte function, cooperation and interaction between antigen presenting cells and CD4+ T cells are impaired in uremia. Moreover, dysregulation at the TCR/CD3 receptor level in uremia may result in an inadequate expression of adhesion and accessory or co stimulatory molecules, and thereby may cause the blunted signaling pathway $(10,20)$. A functional defect of the B7/D28 pathway could contribute to this effect, because in healthy people a single responsive haplotype inherited as a dominant trait is sufficient for a normal antibody response (21). In addition, dialysis patients have reduced cellular immunity, being attributable to reduced life span of lymphocytes, lymphocytopenia, lymphocyte transformation, and suppressor lymphocytes (17). In concordance with these findings, recently, Litjens et al. (22) and Armstrong et al. (23) have reported higher CD4+ counts to be associated with a higher likelihood of patients to develop an antibody response after hepatitis $B$ vaccination. Very recently, it was shown that not only higher CD4+ lymphocyte count but CD4+/CD8+ ratio was also associated with higher seroconversion in HD patients who were vaccinated with HBV vaccine (17). As 
an interesting finding, the current study has shown that increased Hs-Crp levels was positively associated with seroconversion. Thus, in the light of all these findings. it could be speculated that because of depressed immunity, dialysis patients are not able to respond to hepatitis $B$ vaccination, and when they respond, they have lower antibody titers and do not maintain adequate antibody levels over time (7).

The present study showed that blood urea nitrogen, creatinine and albumin levels were positively associated with the response to HBV vaccine. Previously, serum albumin levels were shown to be associated with better seroconversion in HD patients $(1,5,24,25)$. Thus, the current findings could be explained in the context of a relationship between better nutritional status and better vaccination response.

This study has limitations that deserve to be mentioned. Firstly, since the study has a retrospective design the reliability of potential confounders may be questioned. However, in our country it is mandatory to record data about demographics, laboratory parameters and vaccination status and these data are checked regularly by the ministry of health. Secondly, since the study has a cross-sectional design, the findings do not prove a cause and effect relationship. Additionally, reliable information about the brand of vaccines is not available and it is probable that vaccine brands are heterogeneous. Lastly, although no bleeding event was reported in the medical records of the patients during the study period, routine endoscopy or colonoscopy was not available.

In conclusion, EPO resistance was negatively associated with anti-HBs levels and seroconversion. More studies are needed to highlight the underlying mechanisms regarding EPO resistance and response to $\mathrm{HBV}$ vaccination in HD patients.

\section{Acknowledgements}

There is no acknowledments.

\section{Authors' Contribution}

The author Baris Afsar, solely responsible for the writing, drafting and final approval of the manuscript.

\section{Financial Disclosure}

The authors do not declare any financial disclosure.

\section{Funding/Support}

The authors do not declare any funding/support.

\section{References}

1. Afsar B, Elsurer R, Eyileten T, Yilmaz MI, Caglar K. Antibody response following hepatitis B vaccination in dialysis patients: does depression and life quality matter? Vaccine. 2009;27(42):5865-9.

2. DaRoza G, Loewen A, Djurdjev O, Love J, Kempston C, Burnett S, et al. Stage of chronic kidney disease predicts seroconversion after hepatitis B immunization: earlier is better. Am J Kidney Dis. 2003;42(6):1184-92.

3. Lin HH, Liao HW, Lin SK, Wang LY. HLA and response to booster hepatitis $\mathrm{B}$ vaccination in anti-HBs-seronegative adolescents who had received primary infantile vaccination. Vaccine. 2008;26(27-28):3414-20.

4. Wang LY, Lin HH. Ethnicity, substance use, and response to booster hepatitis B vaccination in anti-HBs-seronegative adolescents who had received primary infantile vaccination.J Hepatol. 2007;46(6):1018-25.

5. Kara IH, Yilmaz ME, Suner A, Kadiroglu AK, Isikoglu B. The evaluation of immune responses that occur after HBV infection and $\mathrm{HBV}$ vaccination in hemodialysis patients. Vaccine. 2004;22(2930):3963-7.

6. Agrawal S, Gollapudi P, Elahimehr R, Pahl MV, Vaziri ND. Effects of end-stage renal disease and haemodialysis on dendritic cell subsets and basal and LPS-stimulated cytokine production. Nephrol Dial Transplant. 2010;25(3):737-46.

7. Chow KM, Law MC, Leung CB, Szeto CC, Li PK. Antibody response to hepatitis B vaccine in end-stage renal disease patients. Nephron Clin Pract. 2006;103(3):c89-93.

8. Girndt M, Kohler H, Schiedhelm-Weick E, Schlaak JF, Meyer zum Buschenfelde KH, Fleischer B. Production of interleukin-6, tumor necrosis factor alpha and interleukin-10 in vitro correlates with the clinical immune defect in chronic hemodialysis patients. Kidney Int. 1995;47(2):559-65.

9. Pahl MV, Gollapudi S, Sepassi L, Gollapudi P, Elahimehr R, Vaziri ND. Effect of end-stage renal disease on B-lymphocyte subpopulations, IL-7, BAFF and BAFF receptor expression. Nephrol Dial Transplant. 2010;25(1):205-12.

10. Peces R, de la Torre M, Alcazar R, Urra JM. Prospective analysis of the factors influencing the antibody response to hepatitis B vaccine in hemodialysis patients. Am J Kidney Dis. 1997;29(2):239-45.

11. Smrzova J, Balla J, Barany P. Inflammation and resistance to erythropoiesis-stimulating agents--what do we know and what needs to be clarified? Nephrol Dial Transplant. 2005;20 Suppl 8:viii2-7.

12. Panichi V, Rosati A, Bigazzi R, Paoletti S, Mantuano E, Beati S, et al. Anaemia and resistance to erythropoiesis-stimulating agents as prognostic factors in haemodialysis patients: results from the RISCAVID study. Nephrol Dial Transplant. 2011;26(8):2641-8.

13. Lopez-Gomez JM, Perez-Flores I, Jofre R, Carretero D, RodriguezBenitez P, Villaverde M, et al. Presence of a failed kidney transplant in patients who are on hemodialysis is associated with chronic inflammatory state and erythropoietin resistance. J Am Soc Nephrol. 2004;15(9):2494-501.

14. Lopez-Gomez JM, Portoles JM, Aljama P. Factors that condition the response to erythropoietin in patients on hemodialysis and their relation to mortality. Kidney Int Suppl. 2008;(111):S75-81.

15. Del Vecchio L, Pozzoni P, Andrulli S, Locatelli F. Inflammation and resistance to treatment with recombinant human erythropoietin. J Ren Nutr. 2005;15(1):137-41.

16. Stenvinkel P. Anaemia and inflammation: what are the implications for the nephrologist? Nephrol Dial Transplant. 2003;18 Suppl 8:viii17-22.

17. Sari F, Taskapan H. Good response to HBsAg vaccine in dialysis patients is associated with high $\mathrm{CD} 4+/ \mathrm{CD} 8+$ ratio. Int Urol Nephrol. 2012;44(5):1501-6.

18. Descamps-Latscha B, Chatenoud L. T cells and B cells in chronic renal failure. Semin Nephrol.1996;16(3):183-91.

19. Rahman F, Dahmen A, Herzog-Hauff S, Bocher WO, Galle PR, Lohr HF. Cellular and humoral immune responses induced by intradermal or intramuscular vaccination with the major hepatitis $\mathrm{B}$ surface antigen. Hepatology. 2000;31(2):521-7.

20. Stachowski J, Pollok M, Barth C, Maciejewski J, Baldamus CA. Non-responsiveness to hepatitis $B$ vaccination in haemodialysis patients: association with impaired TCR/CD3 antigen receptor expression regulating co-stimulatory processes in antigen presentation and recognition. Nephrol Dial Transplant.1994;9(2):144-52.

21. Girndt M, Kohler H, Schiedhelm-Weick E, Meyer zum Buschenfelde $\mathrm{KH}$, Fleischer B. T cell activation defect in hemodialysis 
patients: evidence for a role of the B7/CD28 pathway. Kidney Int. 1993;44(2):359-65.

22. Litjens NH, Huisman M, van den Dorpel M, Betjes MG. Impaired immune responses and antigen-specific memory CD4+ T cells in hemodialysis patients. J Am Soc Nephrol. 2008;19(8):1483-90.

23. Armstrong KE, Bush HM, Collins JD, Feola DJ, Caldwell GC, Thorn ton AC. Role of CD4 count in immunity development after hepa- titis A and B vaccination among HIV-infected patients: Kentucky, 2002-2007. J Int Assoc Physicians AIDS Care (Chic). 2010;9(3):179-86.

24. Brown CM, Donlon S, O'Kelly P, Casey AM, Collier C, Conlon PJ, et al. A prospective study of hepatitis B vaccination - a comparison of responders versus nonresponders. Ren Fail. 2011;33(3):276-9.

25. Chin AI. Hepatitis B virus vaccine response in hemodialysis: baseline patient characteristics. Hemodial Int. 2003;7(4):296-303. 